\title{
Da Vinci's observations of soaring birds
}

Philip L. Richardson

Citation: Physics Today 70, 11, 78 (2017);

View online: https://doi.org/10.1063/PT.3.3773

View Table of Contents: http://physicstoday.scitation.org/toc/pto/70/11

Published by the American Institute of Physics

\section{Articles you may be interested in}

The relentless pursuit of hypersonic flight

Physics Today 70, 30 (2017); 10.1063/PT.3.3762

Ship tracks

Physics Today 70, 80 (2017); 10.1063/PT.3.3774

A reminder of the powers of $\pi$

Physics Today 70, 13 (2017); 10.1063/PT.3.3748

In celebration of llya Lifshitz

Physics Today 70, 44 (2017); 10.1063/PT.3.3764

Ships cause their own stormy seas

Physics Today 70, 20 (2017); 10.1063/PT.3.3755

Preparing physics students for 21st-century careers

Physics Today 70, 38 (2017); 10.1063/PT.3.3763

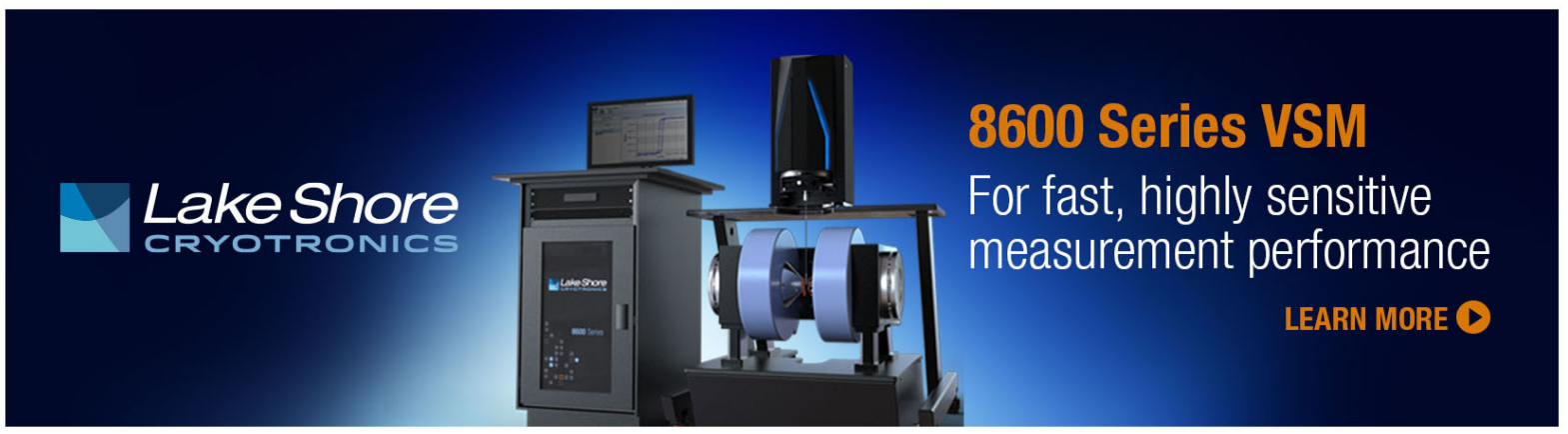




\title{
Da Vinci's observations of soaring birds
}

\author{
Philip L. Richardson
}

\section{More than half a millennium ago, the great polymath Leonardo da Vinci sketched and described a maneuver that birds use to extract energy from a gradient in wind speed.}

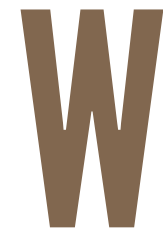

ith only a minimal flapping, the wandering albatross can circumnavigate the globe. During its peregrinations over the Southern Ocean, the seabird exploits wind shear - the gradient of wind speedto extract energy for its sustained flight. That same maneuver, called dynamic soaring, is used by pilots of radio-controlled gliders. In flights that take advantage of the shear associated with wind blowing over mountain ridges, the gliders reach air speeds of an astonishing $500 \mathrm{mph}$. Engineers are currently developing autonomous unmanned vehicles that can use the technique to supplement different sources of energy for sustained flight over the oceans. Possible applications include environmental monitoring, surveillance, and search and rescue.

\section{The answer is blowin' in the wind}

Dynamic soaring, as exemplified by the flight of the wandering albatross and other seabirds, typically has several phases, as illustrated in figure 1. The bird, flying near the ocean surface, turns into the wind and then climbs upwind, crossing the wind-shear layer at a shallow angle. Once above the shear layer, the bird turns downwind and descends across the wind shear into the region of calm air. There it turns around to again head in the windward direction.

As the figure shows, an albatross can gain air speed as it executes a climb-and-descent cycle across the wind-shear layer. The step that imparts kinetic energy to the bird is the banked downwind turn executed high up, where the wind is relatively strong. In essence, the albatross is reflecting off a massive wall moving toward it. The wall of wind transfers some of its kinetic energy to the bird but is essentially unaffected by the interaction. In actual soaring flight, much or all of the bird's kinetic-energy gain is dissipated by drag forces, so the flight is energy neutral.

The albatross in figure 1 is circling in a schematic hover mode. With a slight alteration in its flight path, it can travel in any direction relative to the wind. Indeed, albatrosses often use dynamic soaring to fly across the wind and can sustain speeds of $20 \mathrm{~m} / \mathrm{s}$ doing so. Typically, as they climb and descend across the wind shear, their horizontal velocity component is tilted at an angle relative to the across-wind direction. When albatrosses and other seabirds fly directly upwind, they do so in a manner analogous to a tacking sailboat.

Leonardo da Vinci (1452-1519) studied bird flight while attempting to develop human-powered flying machines. He was particularly interested in understanding how birds soar without flapping their wings. Leonardo sketched numerous birds, added comments about patterns of flight, and carefully studied the movement of air and water. Although many people know him for his studies of aerodynamics, few realize that Leonardo was the first to document the dynamic soaring flight maneuver.

\section{A brief history}

Lord Rayleigh is generally credited with the first realistic description of how a bird can extract energy from wind shear for sustained soaring. In a paper from 1883, he analyzed a twolayer geometry as illustrated in figure 1, but recognized that the bird could equally well gain energy from a continuous gradient in wind speed.

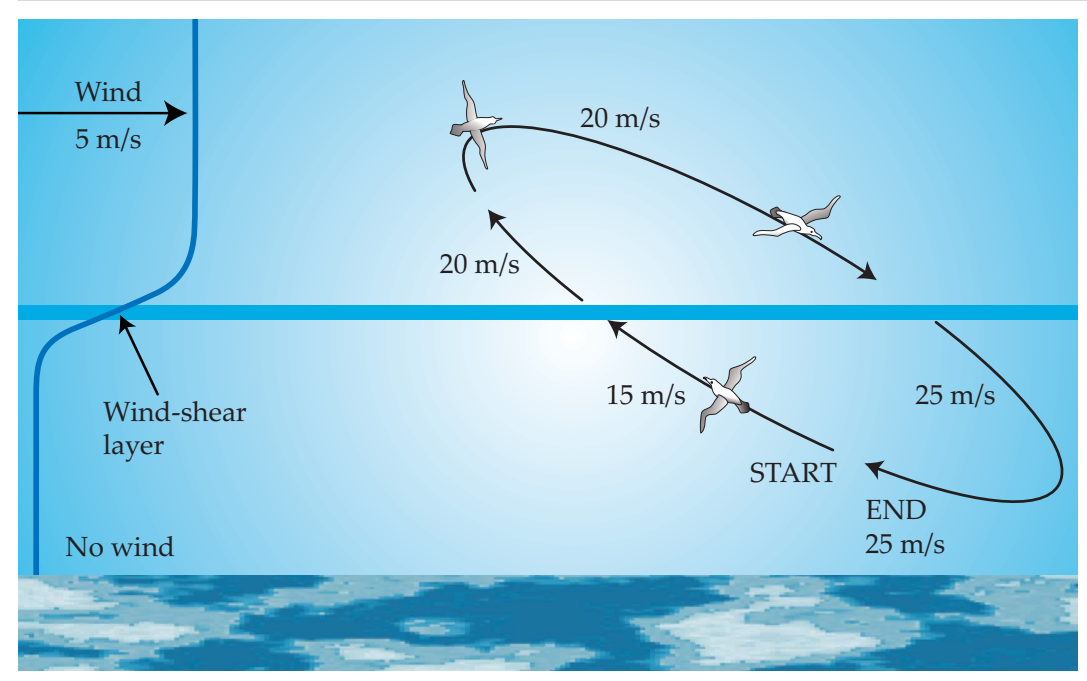

78 PHYSICS TODAY I NOVEMBER 2017
FIGURE 1. ALBATROSSES AND OTHER SEABIRDS can circle almost effortlessly by passing through a gradient in wind speed. In the idealization of dragless flight, they can even pick up speed, as this schematic shows. The zero wind speed in the lower layer represents weak wind located in wave troughs, and the $5 \mathrm{~m} / \mathrm{s}$ wind in the upper layer represents the stronger wind above wave crests. All the specified albatross speeds are air speeds. In particular, as the albatross crosses the shear layer from below, its ground speed does not change, but its air speed increases by $5 \mathrm{~m} / \mathrm{s}$. Similarly, as the bird crosses the shear from above, its speed relative to the high-altitude wind does not change, but air speed increases by an additional $5 \mathrm{~m} / \mathrm{s}$. During the banked downwind turn, ground speed increases from $15 \mathrm{~m} / \mathrm{s}$ to $25 \mathrm{~m} / \mathrm{s}$. Thus one cycle through the wind-shear layer increases the ground speed and air speed by $10 \mathrm{~m} / \mathrm{s}$. 


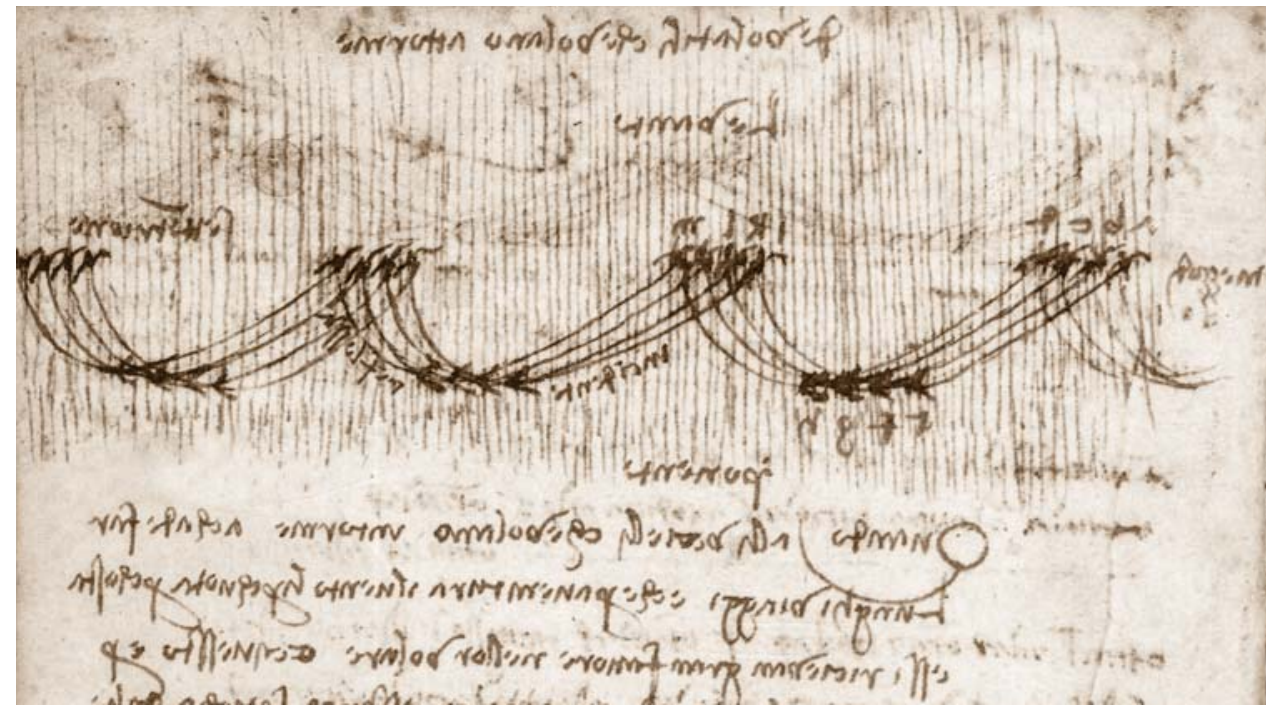

FIGURE 2. ACROSS-WIND dynamic soaring, as illustrated by Leonardo da Vinci in the early 1500 s. The nearly straight vertical lines indicate the direction of the horizontal wind, which is blowing from top to bottom in the figure. Reading from right to left, the first phase of the birds' motion involves an ascent that has components out of the plane of the page and against the flow of the wind. The ensuing descent is partially with the wind. The wind direction and the details of the maneuver are described in Leonardo's notes, written in his characteristic reversed, right-to-left style.

In 1900 Rayleigh summarized bird soaring as part of a review of the mechanical principles of flight. It was an important review, because at the time Rayleigh was one of the few respected scientists to promote human flight. His work included an examination of dynamic soaring of albatrosses and other seabirds. It also had discussions of soaring in wind gusts, soaring in updrafts of warm air currents, and the phenomenon of wind striking sloping land and being deflected upwards.

Nowadays, the principal bone of contention concerning seabird soaring is what primary source of energy powers their flight: Does the energy come from wind shear as described above, or do updrafts deserve the credit? The consensus in the community, in part informed by accurate computer modeling, seems to be that dynamic soaring explains most albatross soaring, at least over the windy Southern Ocean.

\section{Leonardo's notebooks}

Leonardo wanted to discover how birds continuously soar so that he could use the information for developing human flight. Most of his observations of soaring birds were made near Florence, circa 1500-06. A summary of those observations and a description of dynamic soaring can be found in his "Manuscript E," which is dedicated to bird flight and the science of winds. The manuscript was compiled in 1513-15, while Leonardo was living in Rome.

In his manuscript, Leonardo drew pictures of both downwind and across-wind soaring. Figure 2, a reproduction from Manuscript E, folio 40 verso, shows across-wind dynamic soaring by a small flock of migrating birds. In his notes, Leonardo wrote that thrushes and similar birds fly in droves using the maneuver shown in the figure. Here is how he described the undulating motion (translation by John Venerella):

When it happens that birds flying in flocks make long journeys, and the wind, by chance, strikes them on the side, these receive a great favor in their flying. And this is because the flying is done by bounds [undulations] and without the aid of the wings since their incident motion is made beneath [the course of] the wind, with their wings somewhat narrowed, and along the direction of the destined journey. But the reflected motion is made above the [course of the] wind, and with the wings opened, it rises upward, against the approach of the wind and so this wind penetrates beneath the bird, lifting it toward the sky, like a wedge that penetrates under a heavy object placed on top of it.

The "reflected motion" terminology Leonardo used is reminiscent of the hard-wall-reflection picture described earlier, though evidently his preferred simile for the wind's action on the birds was a wedge.

In Manuscript E, folio 40 recto, Leonardo illustrated downwind dynamic soaring. Although he mentioned several land birds in the manuscript, he did not name the downwindsoaring species he drew. Indeed, he identified only one bird with a specific time and place: a "cortone," a bird of prey he saw on his way to Fiesole, near Florence, on 14 March 1505.

Leonardo did not mention an increase of wind speed with altitude in his notes accompanying the dynamic soaring sketches, so he may not have recognized wind shear as being crucial to soaring. But in another notebook entry, he did recognize that wind speed increases with altitude. As he observed, "Birds always fly low when the course of the wind is contrary to their path and this teaches us how the wind is more powerful at a height than low down." Of course, at the beginning of the 16th century, Leonardo could not have conceptualized dynamic soaring with the precision of modern science. He was the first, though, to illustrate and describe an energy-harvesting maneuver important to seabirds and engineers alike.

\section{Additional resources}

- Biblioteca Leonardiana, "e-Leo: History of Science and Technology Digital Archive," www.leonardodigitale.com/index .php?lang=ENG.

- L. Rayleigh, "The Wilde Lecture: The mechanical principles of flight," Mem. Proc. Manch. Lit. Philos. Soc. 44, memoir no. 5 (1899-1900).

- J. D. Anderson Jr, A History of Aerodynamics and Its Impact on Flying Machines, Cambridge U. Press (1997).

- L. da Vinci, The Manuscripts of Leonardo da Vinci in the Institut de France, J. Venerella, trans., Ente raccolta vinciana (1999-2007).

- D. Laurenza, Leonardo on Flight, J. M. Reifsnyder, trans., Giunti (2004).

- P. L. Richardson, "How do albatrosses fly around the world without flapping their wings?," Prog. Oceanogr. 88, 46 (2011). PT 